\title{
Nanokompozit Kaynağı ve Uygulama Alanı Olarak Bitkiler
}

\author{
Plants as a Nanocomposite Source and Field of Application \\ Yiğit KÜÇÜKÇOBANOĞLU ${ }^{1}$ D, Lale YILDIZ AKTAŞ ${ }^{1}$ \\ ${ }^{1}$ Ege Üniversitesi, Fen Fakültesi, Biyoloji Bölümü, 35040, İzmir, Türkiye
}

$\ddot{O} \mathbf{z}$

Nanokompozitler, nanoboyutta iki farklı materyalin birleşmesiyle oluşur. Nanokompozitler tasarlanabilir eşsiz özellikleri ve değiştirilebilir fonksiyonları nedeniyle birçok endüstride kilit rol oynamaktadırlar. Nanokompozit materyallerin üretiminde kaynak olarak kullanılan bitkiler aynı zamanda nanokompozit materyaller için uygulama alanı da oluşturmaktadırlar. Artan hammadde ihtiyacını karşılama ve ekolojik uyumlu alternatif nanomateryal üretiminde, selüloz, lignin gibi birçok bitkisel kaynaklı nanomateryal dikkat çekmektedir. Bitkisel üretim süreçlerinde nanokompozitler, agrokimyasalların toksisitesinin azaltılması, bitki büyüme düzenleyicileri ve mineral besleyicilerin taşınımı, kontrollü ve hedeflenmiş pestisit salınımında kullanılmaktadırlar. Bu derleme, nanokompozit kaynağı olarak kullanılan bitkisel materyaller ve nanokompozitlerin bitkisel üretimde kullanımı konusundaki son gelişmelere odaklanmıştır.

Anahatar Kelimeler: Nanokompozit, Polimer, Nanoteknoloji, Bitki

\begin{abstract}
Nanocomposites are hybrid materials which formed by combining two different materials at nanoscale. Nanocomposites, play a key role in several industries due to their unique devisable properties and modifiable functions. Plants are both source of nanocomposite material production and application field of nanocomposite materials. Many plant derived nanomaterials such as cellulose, lignin etc. draw attention to resolve increasing needs of raw material, and production of ecologically compatible alternative nanomaterials. In crop production processes, nanocomposites are used to reduce the toxicity of agrochemicals, plant growth regulators and mineral nutrient transport, controlled and targeted agrochemical release. This review focused on the latest developments in the use of plant materials which are used as nanocomposite sources, and benefits of nanocomposites in plant production.
\end{abstract}

Keywords: Nanocomposite, Polymer, Nanotechnology, Plant

\section{Giriş}

Nanoteknoloji ilk kez 1960 yılında fizikçi Richard Feynman'ın ‘There's Plenty of Room at the Bottom' adlı konuşmasında atomik blokların moleküler düzeyde kullanımını önermesi ile gündeme gelmiştir [1]. Nanoteknolojinin ilk tanımı ise bu konuşmadan yaklaşık 15 yıl sonra 1974 yılında Prof. Taniguchi tarafından yapılmıştır [2]. Bu tanıma göre "Nanoteknoloji" bir atom veya bir molekül tarafından materyallerin ayrılması, birleştirilmesi ve bozunması işlemleridir. Nanoteknoloji temel olarak nanometre boyutundaki yapıların dizaynı, üretimi, karakterizasyonu ve uygulanmasını kapsayan bir alandır. Günümüzde hızla gelişen bu teknoloji moleküler seviyede - genellikle atom düzeyinde - araçlar, materyaller ve yapılar üreten multidisipliner bir alan oluşturmaktadır. En az bir boyutu 100 nm'den küçük olan yapıları ifade eden nanomateryaller, küçük boyutları ve yüksek yüzey-hacim oranına sahip olmaları nedeniyle, yığın materyallere göre fizikokimyasal özellikleri bakımından oldukça farklıdırlar. Bu boyut-bağımlı fizikokimyasal özellikerin yığın materyallere göre değişkenlik göstermesi nanoürün ve nanomateryal üretiminin hızla artmasına neden olmaktadır [3]. 
Nanomateryaller genel olarak yapı taşlarına göre, karbon-bazlı (organik), metal ve metal oksit-bazlı (anorganik) veya kompozit (hibrit) materyaller şeklinde sınıflandırılmaktadırlar [4, 5]. Karbon-bazlı nanomateryaller genellikle karbondan oluşan, fullerenler ve karbon nanotüpler gibi küre, elipsoid veya tüp şeklinde bulunabilen nanomateryallerdir. Metal ve metal oksit-bazlı nanomateryaller, birkaç nanometre boyutundaki gümüş, altın, çinko oksit, demir oksit ve kuantum noktalar gibi materyalleri kapsamaktadırlar. Birden fazla bileşenden oluşan kompozit nanomateryaller ise yaygin olarak nanokompozit olarak isimlendirilmektedir. $\mathrm{Bu}$ nanomateryaller organik-organik, organik-anorganik veya anorganik-anorganik bağlantılar ile oluşabilmektedirler.

Kitosan, polilaktik asit ve hidroksi etil metakrilat bazlı nanomateryaller yaygın olarak kullanılan nanokompozitlere örnek olarak gösterilebilir. Bu nanomateryaller geleneksel polimerlerden farklı olarak daha kısa sürede ve daha az ham madde ile kolay hazırlanabilmektedir. Ayrıca, biyolojik s1vılarda yüksek stabiliteye sahip olan kompozit nanomateryaller biyobozunurluk, yenilenebilirlik ve biyouyumluluk gibi özelliklerede sahiptir [6, 7]. Bu özelliklerin geliştirilebilir olması, kompozit materyallerin tarım, enerji, kozmetik ve ilaçların dahil olduğu çeşitli sektörlerde kullanımını sağlamaktadır (Şekil 1). Ayrıca nanokompozitlerin, otomotiv, uzay ve havacılık sektörlerinde, yüzey kaplamaları ve güçlendirilmiş materyal olarak, savunma sanayisinde ise 1sı yalıtım materyali olarak yapılan çalışmaları bildirilmiştir [8].

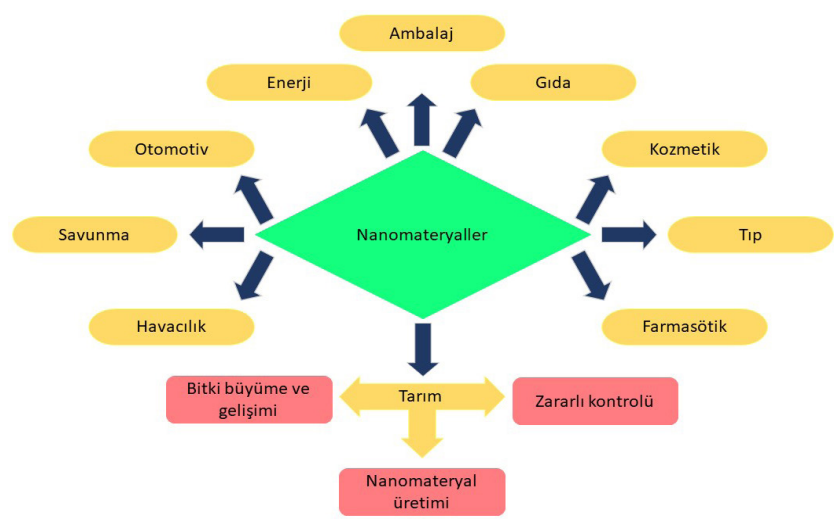

Şekil 1: Nanomateryallerin çeşitli sektörlerde kullanım alanları.

\section{Nanokompozitlerin Özellikleri}

Kompozit materyaller, birbirinden farklı özellikler taş1yan iki veya daha fazla materyalin bir araya gelmesi ile üretilen hibrit materyallerdir. Kompozit materyallerin üretim amacı birbiri içerisinde çözünmeyen materyallerden yeni ve geliştirilmiş özelliklere sahip bir materyal elde etmektir. Bu özellikler, dayanıklılık, esneklik ve boyutsal kararlılık gibi mekanik özellikler, termomekanikal özellikler ve su geçirgenliği gibi temel özelliklerdir. Kompozitler temelde yapisal olarak, matris adı verilen bir ana materyal ve takviye ismi verilen bir yan materyalden oluşur. Nanoboyutta üretilen bu materyaller boyut karakteristikleri nedeniyle yüzeyler arası adezyonu en üst seviyeye çıkararak, polimer matrisi ve takviye nanomateryal arasındaki ara yüzey etkileşimlerini önemli ölçüde arttırmaktadır. Nanokompozitlerin tasarlanabilir eşsiz yapıları, istenilen özelliğe göre uyarlanmalarını ve konvansiyonel kompozitlerden daha üstün özelliklere sahip olmalarını sağlamaktadır [9]. Nanokompozitler matris yapılarına göre temel olarak üç farklı sınıfa ayrılırlar; seramik matrisli nanokompozitler $\left(\mathrm{Al}_{2} \mathrm{O}_{3} / \mathrm{TiO}_{2}, \mathrm{Al}_{2} \mathrm{O}_{3} / \mathrm{SiO}_{2}, \mathrm{Al}_{2} \mathrm{O}_{3} /\right.$ $\left.\mathrm{SiC}, \mathrm{Al}_{2} \mathrm{O}_{3} / \mathrm{CNT}\right)$; metal matrisli nanokompozitler $(\mathrm{Co} / \mathrm{Cr}$, $\mathrm{Fe}-\mathrm{Cr} / \mathrm{Al}_{2} \mathrm{O}_{3}, \mathrm{Fe}-\mathrm{MgO}$ ); polimer matrisli nanokompozitler (poliester/TiO, polimer/CNT).

Nanokompozitler, otomotiv, elektronik, havacilık, savunma, enerji ve biyoteknoloji gibi birçok endüstriyel sektöre entegre olmuşlardır. Çelikten daha hafif ancak daha dayanıklı olan grafen takviyesi kullanılarak üretilen poliester/ grafen nanokompozitlerin, saf poliestere kıyasla mekanik özelliklerinin geliştiği bildirilmiştir [10]. Yapılan bir diğer çalışmada grafen nanolevha takviyesi yapılmış AlSi10MG alaşımında mukavemetin yaklaşık \%22.5 oranında arttığ bildirilmiştir [11]. Ayrıca bu materyaller, lineer olmayan optikler, batarya katodları, nanoteller, sensörler, bataryalar, biyoseramikler ve enerji dönüşümü gibi yeni uygulamaların önünü açmıştır.

Nanokompozit üretiminde yaygın olarak kullanılan sentetik materyaller alifatik poliesterler, alifatik-aromatik poliesterler, polivinil alkoller, poliesteramidler, polistrenler, nanokiller, cam ve karbon lifler ve karbon nanotüplerdir. Ancak, bu materyallerin kullanımı; yağ ve gaz kaynaklarının azalmasına bağlı olarak organik bileşenlerin azalması, materyallerin bozunması veya yakılmasının küresel ısınmaya neden olması, ekonomik olmayan fiyatlar, geri dönüşüm ve tüketiciler için toksisite riskleri gibi birçok sorunu da beraberinde getirmiştir [12]. Bu nedenlerle nanoteknolojik ürünlerde alternatif bir bileşen olarak bitkisel kökenli nanokompozitler öne çıkmıştır.

\section{Bitkisel Kaynaklı Nanokompozitler}

Günümüzde, nanomateryallerin öneminin giderek artması ve artan hammadde ihtiyacı nanokompozit üretiminde kullanılacak yeni materyaller için arayışa neden olmuştur. Bunun sonucunda, sentetik materyallere alternatif olarak organizmalarda bulunan, yağlar, proteinler ve karbohidratlar gibi doğal organik maddeler kullanılmaya başlanmıştır [13]. Miseller ve 
lipozomlar gibi (Fosfo-) lipit bazlı nanomateryaller yüksek çözünürlük aralığı (hidrofilik veya lipofilik) gibi değiştirilebilen özellikleri sayesinde en çok uygulanan nanomateryaller arasında yer almaktadırlar. Protein bazlı nanomateryaller ise genellikle misel benzeri, kendiliğinden oluşma özelliği olan moleküller aracıllı̆̆ ile sentezlenirler. Polissakkaritler; bitkilerin (pektin, zamk gibi), hayvanların (kitosan, kondroitin sülfat gibi), alglerin (alginat) ve mikroorganizmaların (dekstran) yapısında doğal olarak bulunan bileşiklerdir. Organizmalar arac1lığ 1 ile elde edilen bu doğal organik materyaller, nanoboyuta indirgenerek nanokompozit yapılarında takviye elemanı veya matris olarak görev alabilirler. Bu şekilde elde edilen nanokompozitler ile ilgili en dikkat çekici özellik, sürdürülebilir ve tamamen bozunur olmalarıdır. Kullanım ömürleri tükendiğinde doğada kolaylıkla dağılmakta veya bileşenlerine ayrılmaktadırlar. Nişasta, lignin, selüloz, asetat, polilaktik asit, polihidroksialkanoat, polihidroksibütirat gibi doğal kaynaklardan elde edilen polimerler bozunur olarak sınıflandırılabilir [9]. Bu nanokompozitler, üretim hızını arttırmakta ve çevresel uyumlu geri dönüşüm sağlamaktadır [14]. Çevresel kaygıların artması ve petrokimyasal kaynakların azalması gibi nedenlerle, bitkisel hammaddelerden yenilenebilir polimer materyallerin geliştirilmesi materyal bilimi için önemli bir atılım olmuştur [15].

Bitkisel kaynaklı nanokompozit üretiminde kullanılan doğal lifler yaygın olarak selüloz bileşenli nanokompozitlerin ya da selüloz nanokristallerin elde edilmesinde kullanılmaktadır. Organik bir bileşik olan selüloz, bitkilerde hücre çeperinin yapısal bileșenidir. Selüloz gibi doğal polisakkaritlerin fiziksel, kimyasal ve fonksiyonel özellikleri nedeniyle çok yönlü polimerler olduğu düşünülmektedir. Genel olarak kağıt yapımında kullanılmasına karşın, şu anda selülozik kütleden asit hidrolizi ile biyo-dizel üretimi [16] için ilgi çekici bir kaynak konumuna gelmiştir. Selüloz nanolifleri, yüksek derecede kristal yapıları ve sentetik nanoliflerden farklı boyutları sayesinde nanoteknoloji ile ilgilenen araştırıcıların dikkatini çekmektedir. Araştırıcılar, selüloz nanoliflerin birçok alanda şeffaf ve aşırı güçlü filmler olarak kullanım olanaklarını araştırmaktadırlar. Selülozik nanoliflerin nanokompozitlerde takviye olarak kullanılmaya başlaması yaklaşık 20 yıl öncesine dayanmaktadır [17]. Literatürde nanoliflerin, nanokristal flamanlar, nanokristaller hatta monokristaller olmak üzere farklı tanımları mevcuttur. Bu kristalitler, nanoölçüdeki boyutlarına rağmen mikrolifler, mikrokristaller veya mikrokristalitler olarak da isimlendirilmektedir. Bu nanolifler, kaplama bileșenleri ve optik filmlerin yapımında kullanılmakadır. Ayrıca, başta biyomedikal, kozmetik, gıda ve farmasötik endüstrileri olmak üzere değişik alanlarda kullanımları da araştırma konusudur [18]. Selüloz ve türevleri, alginat, pektin, nişasta, pullulan gibi çeşitli polisakaritler ambalaj filmleri yapımı için aday nanokompozit kaynakları olarak test edilmektedir [19].

Bitkisel kaynaklı nanokompozitler, yeni nesil materyal, ürün ve proseslerin gelişiminde önemli bir rol oynamaktadır. $\mathrm{Bu}$ materyaller, halen kullanılmakta olan petrol bazlı hammaddeler tarafindan domine edilen ürün pazarına, sürdürülebilir eko-verimli ürünler olarak dahil olmuştur. Gelecek yıllarda bu materyallerin petrol bazlı ürünlerin yerini almaları beklenmektedir [20]. Bu nanokompozitlerin endüstriyel kullanımının artması, çeşitli tarımsal uygulamalarda kullanılmasının önünü açmıştır. Bitkiler için toksik etkisi olabilen katkı maddelerinin uygulanma miktarını azaltmak için bitkisel kaynaklı nanokompozitler kullanılabilir. Ayrıca, bu nanomateryaller, sera gazı emisyonlarının, karbondioksit, nitrik oksit ve metan gibi partiküllerin salınımını azaltmak için de kilit bir role sahiptir [21].

\section{Bitkisel Üretimde Nanokompozit Uygulamaları}

Günümüzde, gıda ve beslenme kalitesinin yoğun agrokimyasal kullanımından etkilendiği belirtilmektedir. Bununla birlikte, modern tarım bitki büyümesini desteklemek ve bitki verimliliğini artırmak için katkı maddelerine ihtiyaç duymaktadır [21]. Yapılan çalışmalarda, gübrelerin kontrollü salınımı [22] ve bitkileri pest ve patojenlere karşı korumada görevli taşıyıcı ajanların kullanımı [23, 24] ile besin güvenliği ve kalitesinin gelişimi konularına değinilmiştir [25]. Agrokimyasallar için üretilen nanokompozitler, spreyleme gibi doğrudan bitki ile etkileşime girmesini sağlayarak kullanılabilir [26]. Ayrıca bu materyaler, taşıyıcı sistemler aracılığı ile aktif moleküllerin kontrollü salınım mekanizmaları olarak da kullanılabilir [27]. Günümüzde, bitkilere uygulanan geleneksel agrokimyasallardaki aktif moleküller, toprak yıkaması, fotoliz, hidroliz ve biyodegreadasyon gibi olaylarla bozunmaktadır ve bu moleküllerin sadece küçük bir kısmının hedefe ulaşmasına neden olmaktadır [5]. Agrokimyasalların daha etkili olabilmesi için yüksek dozlarda ve miktarda uygulanması, çevresel kirliliğin temel kaynaklarından birini oluşturmaktadır. Nanomateryaller, taşınacak maddeyi diş ajanlardan koruyacak şekilde tasarlanabilir, bitki doku ve hücrelerine kolaylıkla girebilir ve gerekli dozda taşınan maddenin salınımını yapabilirler. Nanokompozitlerin, taşıyıcı sistemler olarak kullanımının daha yüksek verim ve çevre güvenliği sağlaması öngörülmektedir [28]. Örneğin, herbisitler için kompozit nanotaşıyıcı kullanımı daha etkili yabanc1 ot kontrolü ve hedef olmayan organizmalarda daha düşük toksik etki göstermiştir [29]. Turp ve mısır bitkilerine uygulanan, katı lipit nanopartikülleri ile kaplanan simazin ve atrazin herbisitlerinin 10 kat seyreltmeye rağmen yabancı otlara karşı etkili olduğu belirtilmiştir [30]. İmazapik 
ve imazapir herbisitlerinin kitosan ile enkapsülasyonu sonrasında ise Allium cepa bitki hücrelerinde genotoksisitede \%100'e yakın bir düşüş olduğu gözlemlemiştir [29]. Ayrıca nanotaşıyıcılar, fungusitler [31] ve insektisitler [32] gibi diğer pestisit türlerinin biyolojik etkisini ve stabilitesini arttırmak için de kullanılabilir. Bu nanotaşıyıcılar, kimyasal ajanların fotoliz ve hidroliz gibi degredasyon süreçlerine karşı korunmasinda ve hedef olmayan organizmalarda pestisit toksistesini azaltmada kulanılmaktadır [33]. Nano boyutta kimyasal ajanların modifiye edilmesi, artan yüzey-hacim oranı ile birlikte etkinin artmasınına katkı sunabileceğinden, hibrit nanomateryaller gelecekte bitki koruma ve ürün veriminde önemli avantaj sağlayacaktır.

Polimer nanopartiküller ve nanokompozitler pestisitlerin, bitki besleyicilerinin ve ilaçların dağılım etkinliğini arttırmak için önemli bir potansiyele sahiptir. Bu konuda halen kullanılan ve geniş ölçekte kullanılma potansiyeli bulunan bazı nanokompozitler Tablo 1 de özetlenmiştir.

Polimer ve/veya kompozit materyallerin diğer nanomateryallere kıyasla artan boyutları, bitkilerde taşı1ıı sistemler olarak kullanımı ile ilgili birçok soru ortaya çıkarmaktadır
[34]. Örneğin, nanomateryallerin bitki hücrelerine nasıl girdiği ve bu nanopartiküllerin hedeflenen bölgelere nasıl taşındığı belirtilmelidir. Bitkilerde bulunan hücre çeperi selülozik materyalden oluşan ve yaklaşık $30 \mathrm{~nm}$ [35] çapında porlardan oluşan seçici geçirgen olmayan bir yapıdır. Bu nedenle, polimer nanopartiküllerin ve nanokompozitlerin boyutu oldukça önemlidir. Boyutları $30 \mathrm{~nm}$ altında olan nanomateryaller kolayca hücre çeperini geçerek plazma membranına ulaşabilir. Plazma membranına ulaşan nanomateryaller, difüzyon veya elektrokimyasal gradiyent ile apoplastik ve simplastik yolaklar sayesinde hedef bölgelere taşınabilir. Yapılan araştırmalarda, bitkilerde $\mathrm{pH}$ duyarlı polimerlerin (örneğin; poli [(met) akrilik asit] ve poli [N,N-dimetilaminoetil (met) akrilat]) çeşitli uygulamalarda etkili oldukları kanıtlanmıştır [36]. Ancak bu polimerlerin karakteristik bozunabilir olmayan karbon omurgaları içermeleri nedeniyle bitkilerde kullanımını sınırlı kalmıştır. Bu, nanomateryallerin, bitkilerde alınım ve taşınım mekanizmasında aydınlatılmasını zorunlu kılmaktadır. Bu sayede nanomateryaller ile ilgili, biyobozunurluk, toksisite ve sürdürülebilirlik konusunda endişeleri azaltmak ve etkilerinin daha iyi anlaşılması mümkün olacaktır.

Tablo 1: Son yıllarda bitkiler üzerinde araştırılan bazı nanokompozit materyaller ve kullanım amaçları

\begin{tabular}{llll}
\hline $\begin{array}{l}\text { Polimer/kompozit } \\
\text { nanomateryal }\end{array}$ & Bitki & Kullanım amacı & Referans \\
\hline $\begin{array}{l}\text { Katı lipid nanopartikülleri } \\
\begin{array}{l}\text { Polimerik kitosan / } \\
\text { tripolifosfat }\end{array}\end{array}$ & $\begin{array}{l}\text { Zea mays } \\
\text { Brassica rapa } \\
\text { Pisum sativum }\end{array}$ & $\begin{array}{l}\text { Çimlenme üzerindeki } \\
\text { etkileri }\end{array}$ & Nakasato et al., 2017 \\
\hline $\begin{array}{l}\text { Y-Poliglutamikasit/ } \\
\text { Kitosan }\end{array}$ & Phaselous vulgaris & $\begin{array}{l}\text { Biyolojikaktivite } \\
\text { üzerindeki etkileri }\end{array}$ & Pereira et al., 2017 \\
\hline Poli(laktik-co-glikolik)asit & Vitis vinifera & $\begin{array}{l}\text { Bitkiye alınımı ve patojen } \\
\text { funguslar üzerindeki } \\
\text { etkileri }\end{array}$ & Valletta et al., 2014 \\
\hline Selüloz/Gümüş & Cucumis melo & Antimikrobiyal aktivite & Fernandez et al., 2010 \\
\hline Polimer kaplıbakır oksit & Lemna gibba & Toksisite mekanizması & Perreault et al., 2014 \\
\hline Gümüş/ Silika & Glycine max & Antifungal aktivite & Nguyen et al., 2016 \\
\hline $\begin{array}{l}\text { Sodyum humat / } \\
\text { Attapulgit/ Poliakrilamid }\end{array}$ & Zea mays & $\begin{array}{l}\text { Bitki büyümesi ve hidroliz } \\
\text { kontrolü }\end{array}$ & Zhou et al., 2017 \\
\hline Üre kaplı hidroksiapatit & Festuca arundinacea & $\begin{array}{l}\text { Bitki besleyicisi ve bitkiye } \\
\text { alınımı }\end{array}$ & Gunaratne et al.,2016 \\
\hline Naftilasetikasit / silika & Triticum aestivum & Kontrollü salınım & Ao et al., 2012 \\
\hline Karbon nanofiber / bakır & Cicer arietinum & Kontrollü salınım & Ashfaq et al., 2017 \\
\hline
\end{tabular}


Nanoteknolojinin kullanımı yeni pestisit formülasyonlarının üretilmesi bu sorunların kontrol edilmesini sağlayabilir [37, 38]. Sentetik pesitistlerin çevresel zararları olmasına karşın hedef zararlılara karşı etkileri yüksektir. İyi tasarlanmış bir formülasyon, hedef spesifikliğini, aktif içerik etkisinin optimize edilmesini ve kalıntı problemini minimuma indirgemeyi sağlar [39]. Ayrıca bu formülasyonlar etken maddenin stabilitesini artırarak mikroorganizmalar tarafindan bozunmasını engelleyebilir. Daha kararlı hale gelen moleküller hedefe istenilen kontrollü salınımı sağlayabilir. [40, 41]. Bu yeni formülasyonlar ile üretilen, salınım/taşıyıcı sistemler özelleştirilebilir. Difüzyon kontrollü, aşınma kontrollü, şişme kontrollü veya bunların kombinasyonu bu özelleştirmelerden bazılarıdır [42]. Araştırmalar, aktif maddelerin boyutunu nano seviyeye kadar küçülmesi nedeniyle nanoformülasyonlu pestisitlerin hedefe yönelik etkisinin geleneksel yöntemlere göre daha yüksek olduğunu belirtmektedir [43, 44]. Aktif maddenin, nano-emülsiyonlar veya nano dispersiyonlarla karıştırılmasıyla ya da nanokapsüller ile birleştirilmesiyle yeni nesil pestisitler üretilir [45]. Polimerik ve lipit nanopartiküllerinin bitki mineral besleyicileri ve pestisit taşıyıcı sistemleri olarak kullanıldığı çalışmalar mevcuttur [46]. Poli (epsilon-kaprolakton) nanopartiküllerinin [47] ve katı lipit nanopartiküllerinin [30] oluşturduğu sistemlerin biyolojik aktivitelerine ilişkin çeşitli araştırmalar yapılmıştır. Bu çalışmalarda, herbisit yüklemesi yapılmış nanomateryallerin yüksek konsantrasyonlarda uygulanmasında dahi, Brassica sp., Raphanus raphanistrum ve Zea mays bitkilerinde fitotoksik etkilerinin düşük olduğu belirtilmiştir $[\mathbf{4 7 , 4 8}]$.

Katı lipit ve polimerik nanokapsüller karbendazim ve tebukonazol ile yüklenerek yeni bir fungusit formülasyonu geliştirilmiştir. Sonuçlar, nanokapsüllerin yüksek yükleme kapasitesi olduğunu ve yaygın olarak kullanılan fungusitler ile kıyaslandığında nanokapsül-fungusitlerin kademeli salınmaları nedeniyle bitki büyümesindeki yan etkilerinin daha düşük olduğu gösterilmiştir [31]. Porlu silikanın, pestisit validamisin ve herbisit 2,4-diklorofeoksiasetat'ın zamana bağl1 kontrollü salınımını sağladığı belirlenmiştir [49]. Sürfaktan bazlı nanoemülsiyonların, pestisit olan beta-cypermetrin ile ilişkili dağıtım mekanizması araştırılmış ve bu nanomateryalin pestisit kararlılığını arttırdığı belirlenmiştir [50]. Feromon metil eugenol içeren nanojellerin ise çok düşük dozlarda etkinlik kaybı olmaksızın meyve pestlerinin kontrol edilmesine neden olduğu ve bu yolla ürün maliyetini düşürdüğü ortaya konulmuştur [51]. Silika-bazlı nanopartiküller bitkilerde, kontrollü agrokimyasal dağıtım ajanları olarak büyük bir potansiyele sahiptir. Porlu içi boş silika nanopartiküllerinin pestisit taşıyıcısı olarak kullanıldığı nanokompozit sisteminde avermektin pestisidinin bitkiye kontrollü salınımı belirlemiştir [52]. Bunların dışında, alginat, selüloz, siklodekstrin, dekstran, pektin ve kitosan gibi biyopolimerler de, agrokimyasallar için taşıyıcı sistemler olarak kullanılmaktadır [23].

Bilimsel veriler, nanomateryallerin bitki koruma için kullanılan katkı maddelerinin fiyatlarının düşmesini, üretim alanlarında besleyici kaybının minimize edilmesini ve besleyici yönetimi ile ürün verimliliğinin artmasını sağladığını göstermektedir [53]. Bu nano-boyutlu ürünlere örnek olarak, besleyici verimini arttırmak için nano enkapsülasyonlu nano-gübreler, su kullanım verimliliğini sağlamak için kil-polimer nanokompozitler gösterilebilir. Bu ürünler diğer organizmalara verilen zararları en aza indirerek nanotarımı desteklemektedir [54].

Nanoteknoloji, taşıma ve kontrollü salınım mekanizmaları dışında, bitki besleyicilerin kontrolü açısından da üretimin önemli bir parçasıdır $[\mathbf{5 5}, \mathbf{5 6}]$. Ancak nanoteknoloji çalışmalarında, bitki büyüme düzenleyicileri ile ilgili olarak sınırlı sayıda çalışma bulunmaktadır. Bitki büyüme düzenleyicileri, bitki veya meyvelerin gelişimini arttırmak için kullanılan giberellinler, oksinler, sitokininler, absisik asit ve etilen gibi sinyal moleküllerdir [57]. Mikropartikül salınım sistemleri brassinosteroid [58] ve naftalen asetik asit [59] için kullanılmaktadır. Liu et al. [60] tarafından çalışmada giberellik asit ile kitosan konjugasyonuna dayalı nanokompozit sisteminde giberellik asitin kontrollü salınımını kararlılığının arttığ belirtilmiştir. Hafez et al. [61] tarafından ise ise inorganik magnezyum-alüminyum katmanlı çift-hidroksit metal ile giberellik asitten oluşan nanohibrid sistemin bu bitki büyüme düzenleyicisinin devamlı salınımı ve yavaş degredasyonunu sağladığını bildirilmiştir.

\section{Sonuç}

Nanokompozit üretimi için bitkisel kaynaklardan yararlanılması gelecekteki olası hammadde sorunlarının aşılmasında önemli bir alternatiftir. Bitkisel polimerlerin kompozit yapımında kullanılması ve nanomateryal sentezinde bitkilerden faydalanılması çevreci bir yaklaşım olmasının yanı sıra, daha ucuz ve kısa süreli üretimi mümkün kılmaktadır. Elde edilen materyaller takviye olarak, eşsiz ve tasarlanabilir nanokompozit üretiminde kullanıma uygundur. Bitki ve nanomateryal etkileşimlerinin aydınlatılması konusundaki ilerlemeler nanoteknolojinin, bitki hastalıkları, gübreleme sistemleri, bitki büyüme ve gelişimi gibi konularda daha fazla ve etkin kullanımının önü açılacaktır. Dahası bitkiler üzerinde nanomateryallerin alınım, birikim ve taşınım mekanizmaları farklı biyomimetik yaklaşımların önünü açmada fayda sağlayabilir. Bu biyomimetik yaklaşımlar sayesinde gelecekte bitki ışık hasat sistemlerinin taklit edilmesi 
ile yapay 1şık hasat sistemleri, enerji dönüşüm sistemleri gibi teknolojik gelişimler sağlanabilir. Bunun yanı sıra, tarımsal sorunların başında yer alan toprak ve su ile ilişkili sorunların önüne geçmek için kullanılması mümkündür. Nanokompozitlerin toprak tuzluluğunun azaltılması ve su kalitesinin iyileştirilmesinde kullanılması ürün veriminin artması sağlanabilir. Bütün bunlarla birlikte nanoteknolojinin fayda/zarar oranının dengelenmesi için gerekli çalışmalar titizlikle yapılmalıdır.

\section{Kaynaklar}

[1] Feynman, R. P., (1960). There's plenty of room at the bottom. Engineering and Science, 23(5), 22-36.

[2] Taniguchi, N., (1974). On the basic concept of nano-technology. In Proc. Intl. Conf. Prod. London, 1974. British Society of Precision Engineering.

[3] Agrawal, U., Sharma, R., Gupta, M., \& Vyas, S. P., (2014). Is nanotechnology a boon for oral drug delivery? Drug Discovery Today, 19(10), 1530-1546.

[4] EPA, (2007). Nanotechnology White Paper. U.S. Environmental Protection Agency publication. Washington, DC.

[5] Nair, R., Varghese, S. H., Nair, B. G., Maekawa, T., Yoshida, Y., \& Kumar, D. S., (2010). Nanoparticulate material delivery to plants. Plant science, 179(3), 154-163.

[6] Draz, M. S., Fang, B. A., Zhang, P., Hu, Z., Gu, S., Weng, K. C., Gray, J. W., \& Chen, F. F., (2014). Nanoparticle-mediated systemic delivery of siRNA for treatment of cancers and viral infections. Theranostics, 4(9), 872.

[7] Mu, L., \& Seow, P. H., (2006). Application of TPGS in polymeric nanoparticulate drug delivery system. Colloids and Surfaces B: Biointerfaces, 47(1), 90-97.

[8] Yılmaz, U., \& Evci, C., (2015). Havacillk ve savunma sektöründe kompozit malzemelerin geleceği. Savunma Bilimleri Dergisi, 14(2), 77-109

[9] Adeosun, S. O., Lawal, G. I., Balogun, S. A., \& Akpan, E. I., (2012). Review of green polymer nanocomposites. Journal of Minerals and Materials Characterization and Engineering, 11(04), 385.

[10] Subaşı, A., Zurnacı, M., Kahyaoğlu, A., \& Demir, E., (2017). Polyester/Grafen Kompozitlerin Mekanik ve Termal Özelliklerinin İncelenmesi. Science and Engineering, 4(3), 472-481.

[11] Kandemir, S., (2018). Grafen Nanolevha Takviyesinin AlSi10Mg Alaşımının Mikroyapı ve Mekanik Özellikleri Üzerine Etkisi. Gazi Üniversitesi Fen Bilimleri Dergisi Part C: Tasartm ve Teknoloji, 6(1), 177-187.

[12] Leja, K., \& Lewandowicz, G., (2010). Polymer Biodegradation and Biodegradable Polymers-a Review. Polish Journal of Environmental Studies, 19(2).

[13] Luykx, D. M., Peters, R. J., van Ruth, S. M., \& Bouwmeester, H., (2008). A review of analytical methods for the identification and characterization of nano delivery systems in food. Journal of Agricultural and Food Chemistry, 56(18), 8231-8247

[14] Pandey, J. K., Chu, W. S., Lee, C. S., \& Ahn, S. H., (2007, October). Preparation characterization and performance evaluation of nanocomposites from natural fiber reinforced biodegradable polymer matrix for automotive applications. In International Symposium on Polymers and the Environment: Emerging Technology and Science, BioEnvironmental Polymer Society (BEPS).

[15] Zhang, X., Do, M. D., Dean, K., Hoobin, P., \& Burgar, I. M., (2007). Wheat-gluten-based natural polymer nanoparticle composites. Biomacromolecules, 8(2), 345-353.

[16] Horuz, A., Korkmaz, A., \& Akınoğlu, G., (2015). Biyoyakıt Bitkileri ve Teknolojisi. Toprak Bilimi ve Bitki Besleme Dergisi, 3(2), 69-81.

[17] Eichhorn, S. J., Dufresne, A., Aranguren, M., Marcovich, N. E., Capadona, J. R., Rowan, S. J., ... \& Gindl, W., (2010). current international research into cellulose nanofibres and nanocomposites. Journal of Materials Science, 45(1), 1.

[18] Manna, U., \& Patil, S., (2009). Borax mediated layer-by-layer self-assembly of neutral poly (vinyl alcohol) and chitosan. The Journal of Physical Chemistry B, 113(27), 91379142.

[19] Kanmani, P., \& Rhim, J. W., (2014). Properties and characterization of bionanocomposite films prepared with various biopolymers and $\mathrm{ZnO}$ nanoparticles. Carbohydrate Polymers, 106, 190-199.

[20] La Mantia, F. P., \& Morreale, M., (2011). Green composites: A brief review. Composites Part A: Applied Science and Manufacturing, 42(6), 579-588.

[21] Lal, R., (2016). Global food security and nexus thinking. Journal of Soil and Water Conservation, 71(4), 85A-90A.

[22] DeRosa, M. C., Monreal, C., Schnitzer, M., Walsh, R., \& Sultan, Y., (2010). Nanotechnology in fertilizers. Nature Nanotechnology, 5(2), 91-91.

[23] Campos, E. V. R., de Oliveira, J. L., \& Fraceto, L. F., (2014). Applications of controlled release systems for fungicides, herbicides, acaricides, nutrients, and plant growth hormones: a review. Advanced Science, Engineering and Medicine, 6(4), 373-387.

[24] Grillo, R., Abhilash, P. C., \& Fraceto, L. F., (2016). Nanotechnology applied to bio-encapsulation of pesticides. Journal of Nanoscience and Nanotechnology, 16(1), 1231-1234.

[25] Fraceto, L. F., Grillo, R., de Medeiros, G. A., Scognamiglio, V., Rea, G., \& Bartolucci, C., (2016). Nanotechnology in agriculture: which innovation potential does it have?. Frontiers in Environmental Science, 4, 20.

[26] Mishra, S., Singh, B. R., Singh, A., Keswani, C., Naqvi, A. H., \& Singh, H. B., (2014). Biofabricated silver nanoparticles act as a strong fungicide against Bipolaris sorokiniana causing spot blotch disease in wheat. PLoS One, 9(5), e97881.

[27] Ihegwuagu, N. E., Sha'Ato, R., Tor-Anyiin, T. A., Nnamonu, L. A., Buekes, P., Sone, B., \& Maaza, M., (2016). 
Facile formulation of starch-silver-nanoparticle encapsulated dichlorvos and chlorpyrifos for enhanced insecticide delivery. New Journal of Chemistry, 40(2), 1777-1784.

[28] Sekhon, B. S., (2014). Nanotechnology in agri-food production: an overview. Nanotechnology, Science and Applications, 7,31 .

[29] Maruyama, C. R., Guilger, M., Pascoli, M., Bileshy-José, N., Abhilash, P. C., Fraceto, L. F., \& De Lima, R., (2016). Nanoparticles based on chitosan as carriers for the combined herbicides imazapic and imazapyr. Scientific Reports, 6, 19768.

[30] de Oliveira, J. L., Campos, E. V. R., Gonçalves da Silva, C. M., Pasquoto, T., Lima, R., \& Fraceto, L. F., (2015). Solid lipid nanoparticles co-loaded with simazine and atrazine: preparation, characterization, and evaluation of herbicidal activity. Journal of Agricultural and Food Chemistry, 63(2), 422-432.

[31] Campos, E. V. R., De Oliveira, J. L., Da Silva, C. M. G., Pascoli, M., Pasquoto, T., Lima, R., ... \& Fraceto, L. F., (2015). Polymeric and solid lipid nanoparticles for sustained release of carbendazim and tebuconazole in agricultural applications. Scientific Reports, 5, 13809.

[32] Elek, N., Hoffman, R., Raviv, U., Resh, R., Ishaaya, I., \& Magdassi, S., (2010). Novaluron nanoparticles: Formation and potential use in controlling agricultural insect pests. Colloids and Surfaces A: Physicochemical and Engineering Aspects, 372(1), 66-72.

[33] Khot, L. R., Sankaran, S., Maja, J. M., Ehsani, R., \& Schuster, E. W., (2012). Applications of nanomaterials in agricultural production and crop protection: a review. Crop Protection, 35, 64-70.

[34] Theato, P., Sumerlin, B. S., O’Reilly, R. K., \& Epps III, T. H., (2013). Stimuli responsive materials. Chemical Society Reviews, 42(17), 7055-7056.

[35] Fleischer, A., O’Neill, M. A., \& Ehwald, R., (1999). The pore size of non-graminaceous plant cell walls is rapidly decreased by borate ester cross-linking of the pectic polysaccharide rhamnogalacturonan II. Plant Physiology, 121(3), 829-838.

[36] Gao, W., Chan, J. M., \& Farokhzad, O. C., (2010). pH-responsive nanoparticles for drug delivery. Molecular pharmaceutics, 7(6), 1913-1920.

[37] Forim, M. R., Costa, E. S., da Silva, M. F. D. G. F., Fernandes, J. B., Mondego, J. M., \& Boiça Junior, A. L., (2013). Development of a new method to prepare nano-/microparticles loaded with extracts of Azadirachta indica, their characterization and use in controlling Plutella xylostella. Journal of Agricultural and Food Chemistry, 61(38), 9131-9139.

[38] Gogos, A., Knauer, K., \& Bucheli, T. D., (2012). Nanomaterials in plant protection and fertilization: current state, foreseen applications, and research priorities. Journal of Agricultural and Food Chemistry, 60(39), 9781-9792.

[39] de Oliveira, J. L., Campos, E. V. R., Bakshi, M., Abhilash, P. C., \& Fraceto, L. F., (2014). Application of nanotechnology for the encapsulation of botanical insecticides for sustainable agriculture: prospects and promises. Biotechnology Advances, 32(8), 1550-1561.

[40] Ghormade, V., Deshpande, M. V., \& Paknikar, K. M., (2011). Perspectives for nano-biotechnology enabled protection and nutrition of plants. Biotechnology Advances, 29(6), 792-803.

[41] Duran, N., \& Marcato, P. D., (2013). Nanobiotechnology perspectives. Role of nanotechnology in the food industry: a review. International Journal of Food Science \& Technology, 48(6), 1127-1134.

[42] Tramon, C., (2014). Modeling the controlled release of essential oils from a polymer matrix - a special case. Industrial Crops and Products, 61, 23-30.

[43] Kah, M., (2015). Nanopesticides and nanofertilizers: emerging contaminants or opportunities for risk mitigation?. Frontiers in Chemistry, 3.

[44] Sarkar, B., Bhattacharjee, S., Daware, A., Tribedi, P., Krishnani, K. K., \& Minhas, P. S., (2015). Selenium nanoparticles for stress-resilient fish and livestock. Nanoscale Research Letters, 10(1), 371.

[45] Frederiksen, H. K., Kristensen, H. G., \& Pedersen, M., (2003). Solid lipid microparticle formulations of the pyrethroid gamma-cyhalothrin - incompatibility of the lipid and the pyrethroid and biological properties of the formulations. Journal of controlled release, 86(2), 243-252.

[46] Kashyap, P.L., Xiang, X. \& Heiden, P., (2015). Chitosan nanoparticle based delivery systems for sustainable agriculture. International Journal of Biological Macromolecules, 77, pp.36-51.

[47] Pereira, A. E., Grillo, R., Mello, N. F., Rosa, A. H., \& Fraceto, L. F., (2014). Application of poly (epsilon-caprolactone) nanoparticles containing atrazine herbicide as an alternative technique to control weeds and reduce damage to the environment. Journal of Hazardous Materials, 268, 207-215.

[48] Oliveira, H. C., Stolf-Moreira, R., Martinez, C. B., Sousa, G. F., Grillo, R., de Jesus, M. B., \& Fraceto, L. F., (2015). Evaluation of the side effects of poly (epsilon-caprolactone) nanocapsules containing atrazine toward maize plants. Frontiers in chemistry, 3.

[49] Liu, F., Wen, L. X., Li, Z. Z., Yu, W., Sun, H. Y., \& Chen, J. F., (2006). Porous hollow silica nanoparticles as controlled delivery system for water-soluble pesticide. Materials Research Bulletin, 41(12), 2268-2275.

[50] Wang, L., Li, X., Zhang, G., Dong, J. \& Eastoe, J., (2007). Oil-in-water nanoemulsions for pesticide formulations. Journal of Colloid and Interface Science, 314(1), pp.230-235.

[51] Bhagat, D., Samanta, S. K., \& Bhattacharya, S., (2013). Efficient management of fruit pests by pheromone nanogels. Scientific Reports, 3.

[52] Hussain, H. I., Yi, Z., Rookes, J. E., Kong, L. X., \& Cahill, D. M., (2013). Mesoporous silica nanoparticles as a biomolecule delivery vehicle in plants. Journal of Nanoparticle Research, 15(6), 1676. 
[53] Meena, R. S., Meena, V. S., Meena, S. K., \& Verma, J. P., (2015). The needs of healthy soils for a healthy world. Journal of Cleaner Production, 560-561.

[54] Mousavi, S. R., \& Rezaei, M., (2011). Nanotechnology in agriculture and food production. Journal of Applied Environmental and Biological Sciences, 1(10), 414-419.

[55] Mukhopadhyay, S. S., (2014). Nanotechnology in agriculture: prospects and constraints. Nanotechnology, Science and Applications, 7, 63.

[56] Prasad, R., Bhattacharyya, A., \& Nguyen, Q. D., (2017). Nanotechnology in sustainable agriculture: recent developments, challenges, and perspectives. Frontiers in Microbio$\log y, 8,1014$.

[57] Pereira, A. E. S., Sandoval-Herrera, I. E., Zavala-Betancourt, S. A., Oliveira, H. C., Ledezma-Pérez, A. S., Romero, J., \& Fraceto, L. F., (2017). $\gamma$-Polyglutamic acid/chitosan nanoparticles for the plant growth regulator gibberellic acid:
Characterization and evaluation of biological activity. Carbohydrate Polymers, 157, 1862-1873.

[58] Quiñones, J. P., García, Y. C., Curiel, H., \& Covas, C. P., (2010). Microspheres of chitosan for controlled delivery of brassinosteroids with biological activity as agrochemicals. Carbohydrate Polymers, 80(3), 915-921.

[59] Tao, S., Pang, R., Chen, C., Ren, X., \& Hu, S., (2012). Synthesis, characterization and slow release properties of O-naphthylacetyl chitosan. Carbohydrate Polymers, 88(4), 1189-1194.

[60] Liu, Y., Sun, Y., He, S., Zhu, Y., Ao, M., Li, J., \& Cao, Y., (2013). Synthesis and characterization of gibberellin-chitosan conjugate for controlled-release applications. International Journal of Biological Macromolecules, 57, 213-217.

[61] Hafez, I. H., Berber, M. R., Minagawa, K., Mori, T., \& Tanaka, M., (2010). Design of a multifunctional nanohybrid system of the phytohormone gibberellic acid using an inorganic layered double-hydroxide material. Journal of Agricultural and Food Chemistry, 58(18), 10118-10123. 